\title{
CASE REVIEW I \\ DECISIÓN SUPERINTENDENCIA \\ DE INDUSTRIA Y COMERCIO SOBRE \\ UNA INVESTIGACIÓN EN CONTRA DE SAYCO \\ (SOCIEDAD DE AUTORES Y COMPOSITORES \\ DE COLOMBIA)
}

FELIPE ABELLO*

Superintendente Delegado para la Protección de la Competencia recomendó sancionar a la sociedad de gestión colectiva Sayco por abusar de su posición de dominio. Investigación (2011-150526).

\section{El CASO}

El 26 de septiembre de 2016, la Delegatura para la Protección de la Competencia ("la Delegatura") de la Superintendencia de Industria y Comercio ("sic") recomendó al Superintendente, en el informe motivado ${ }^{1}$ que puso fin a la investigación en contra de la Sociedad de Autores y Compositores de Colombia-Sayco-y de Jairo Enrique Ruge Ramírez, sancionar a Sayco por haber abusado de su posición de domino. Las posibles sanciones que serían impuestas a Sayco podrían ascender a una suma máxima de cien mil (100.000) salarios mínimos legales mensuales vigentes.

\section{Problema jurídico}

En relación con la infracción del numeral 1 de la Ley 155 de 1959, la Delegatura debió determinar si Sayco, amparándose en un sistema legal para la protección de los derechos de autores y compositores - por medio de (i) la imposición unilateral de tarifas a los usuarios, (ii) el traslado de costos de transacción al autor y (iii) la no concertación de las tarifas con los usuarios-, obstruyó el acceso de agentes al mercado de comunicación pública de obras musicales, afectando a usuarios que utilizan las obras como insumo para el desarrollo de su actividad.

\footnotetext{
* Abogado de la Universidad Javeriana de Colombia. Candidato a maestro en Propiedad Intelectual de la Universidad Externado de Colombia. Contacto: [felipeabellom@gmail.com] y [felipe.abello@est.uexternado.edu.co] Dor: http://dx.doi.org/10.18601/16571959.n22.10.

1 En ejercicio de la función establecida en el numeral 6 del artículo 9 del Decreto 4886 de 2011.
} 
Frente a esta imputación la Delegatura recomendó el archivo al Superintendente de Industria y Comercio, al no encontrar elementos de juicio suficientes que demostraran la ocurrencia de esa conducta.

En lo que tiene que ver con la infracción de los numerales 3 y 6 del artículo 50 del Decreto 2153 de 1992 y el artículo 8 de la Ley 155 de 1959, la Delegatura investigó si Sayco, amparándose en su posición de dominio en el mercado de comunicación pública de obras musicales, habría -mediante (i) la realización de actos abusivos de la posición dominante, dado el carácter obstructivo que tiene subordinar la gestión colectiva para ciertos usos a que se le otorgara un mandato para gestionar colectivamente todos las modalidades de uso del derecho patrimonial de comunicación pública y (ii) la imposibilitación de formas de gestión diferentes a la colectiva, en mercados en los que sería favorable la concurrencia- realizado con ello una conducta exclusoria, tendiente a monopolizar la gestión de las obras, afectado la posibilidad que tienen los titulares de estas de gestionar individualmente sus derechos en el mercado de comunicación pública de obras musicales.

La Delegatura recomendó sanción al Superintendente de Industria y Comercio, al encontrar elementos de juicio suficientes que demostraron la ocurrencia de esa conducta por parte de Sayco, la conducta estuvo llamada a prosperar.

Finalmente, en relación con la persona natural investigada, la Delegatura encontró que Jairo Enrique Ruge Ramírez (gerente de Sayco para la época de los hechos) habría colaborado, facilitado y ejecutado el comportamiento restrictivo desarrollado por Sayco, en los términos del artículo 26 de la Ley 1340 de 2009.

\section{Hechos}

En noviembre del año 2011, el empresario de conciertos Ricardo Leyva Parra denunció a través de medios de comunicación a Sayco por pretender impedir la realización del concierto del grupo musical Aerosmith ${ }^{2}$. Adicionalmente, Leyva Parra sugirió que Sayco se servía de su poder en el mercado para imponer, por distintos mecanismos, tarifas excesivamente elevadas, a la vez que mencionó que Sayco no remuneraba de manera adecuada a los autores y compositores que representaba.

A los anteriores hechos se sumaron las quejas interpuestas por terceras personas, que señalaron que Sayco coaccionaba el pago de tarifas sin motivar la causa del pago ni el monto del mismo, obstruía la gestión individual de obras por parte de las autores y compositores, y cobraba el licenciamiento por la explotación de obras de artistas que no representaba.

Debido a la anterior situación, el Superintentendente Delegado para la Protección de la Competencia impartió la instrucción para adelantar de oficio una averiguación preliminar, mediante memorando radicado con el número 11-150526-0

2 Realizado el 3 de noviembre de 2011 en el Parque Simón Bolívar en la ciudad de Bogotá. 
del 8 de noviembre de 2011, con el fin de establecer si existía evidencia para iniciar una investigación por la realización de prácticas comerciales restrictivas de la libre competencia ejecutadas por parte de Sayco.

\section{TRÁMITE}

Con el fin de surtir la etapa de instrucción, la Delegatura decretó algunas pruebas y denegó otras. Además, durante la actuación se resolvieron algunas solicitudes de nulidad hechas por los investigados, así como algunas solicitudes para presentar garantías por parte de los investigados. Por último, cerrada la etapa probatoria, se llevó a cabo la audiencia ordenada por el artículo 52 del Decreto 2153 de 1992.

\section{ANÁLISIS}

En Colombia, la legislación de derechos de autor permite a los titulares administrar los derechos patrimoniales a través de sociedades de gestión colectiva, por medio de una gestión individual o por medio de cualquier otra forma de gestión. El informe motivado se expresó en los siguientes términos.

En el ordenamiento jurídico colombiano, el Legislador faculta a los autores y/o titulares de obras literarias y artísticas para autorizar de manera previa y expresa la utilización de sus creaciones. Como desarrollo de dicha atribución, se ha previsto que el recaudo de los derechos de autor y sus derechos conexos se realice de manera directa a través de la gestión individual de cada interesado o mediante la gestión colectiva realizada por personas jurídicas instituidas para dicho efecto, denominadas sociedades de gestión colectiva, las cuales encuentran fundamento en el derecho de asociación consagrado en el artículo 38 de la Constitución Política.

Sobre la base de lo anterior, es necesario hacer referencia a las características propias de cada una de esas modalidades de gestión de los derechos de autor.

\section{GeSTiÓn INDIVIDUAL. LA GESTIÓN COLECTIVA NO ES OBLIGATORIA EN COLOMbia}

La gestión individual es la administración de los derechos de autor de contenido patrimonial realizada directamente por el titular. Se refiere al ejercicio natural de las prerrogativas que mediante los artículos 13 de la Decisión 351 de 1993 y 12 de la Ley 23 de 1982 se otorgan al titular de la obra. En relación con las actividades concretas que esta modalidad de gestión comprende, la doctrina especializada ha precisado que incluye dos: de un lado, la de "negociar con el usuario las condiciones de la autorización y conferirla", y del otro, la de "efectuar la recaudación" correspondiente. En relación con lo anterior, el informe motivado precisó: 
... en este proceso se demostró que la gestión de algunas formas de utilización de obras protegidas por el derecho de autor solo puede llevarse a cabo-eficientemente-mediante una sociedad de gestión colectiva. Es el caso de la gestión del derecho por comunicación pública en establecimientos abiertos al público o la ejecución pública en vivo de obras musicales, formas de gestión en las que la intervención de sAYCo es indispensable. Es importante señalar que el material probatorio que permite establecer esta conclusión será referido en el acápite dedicado a exponer las razones que determinan la existencia de una posición de dominio en cabeza de SAYCO; por ahora basta anunciar que dentro de ese conjunto de pruebas se encuentra la confesión de esa persona jurídica en relación con dicho aspecto fáctico.

A diferencia de otros ordenamientos jurídicos, en Colombia no existe dentro del régimen de protección de derechos de autor ninguna norma que establezca que la gestión colectiva es obligatoria.

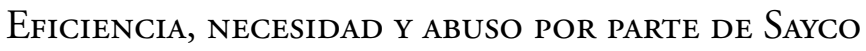 DE LA GESTIÓN COLECTIVA}

De conformidad con la doctrina y la normativa aplicable a los derechos de autor y los pronunciamientos de la Organización Mundial de la Propiedad Intelectual y la DNDA, la gestión colectiva es:

... el sistema de administración de derechos de autor y de derechos conexos por el cual sus titulares delegan en organizaciones creadas al efecto la negociación de las condiciones en que sus obras, sus prestaciones artísticas o sus aportaciones industriales -según el caso- serán utilizadas por los difusores y otros usuarios primarios, el otorgamiento de las respectivas autorizaciones, el control de las utilizaciones, la recaudación de las remuneraciones devengadas y su distribución o reparto entre los beneficiarios.

En Colombia, el marco jurídico de la gestión colectiva se encuentra establecido en el capítulo xi de la Decisión 351 de 1993, el capítulo Xvi de la Ley 23 de 1982, el capítulo in de la Ley 44 de 1993 y el Decreto 3942 de 2010.

La normativa citada, así como las precisiones realizadas por la doctrina, permiten aclarar que la gestión colectiva se desarrolla por intermedio de personas jurídicas que reciben de un número representativo de titulares de derechos de autor el encargo de gestionar sus derechos de contenido patrimonial y de actuar en su representación con ese propósito. Así facultadas, la función de las personas jurídicas en cuestión consiste en negociar con los potenciales usuarios de las obras incluidas en su repertorio las condiciones de utilización correspondientes -es decir, la forma en que se llevará a cabo el uso y la remuneración que se seguirá de ello-y, acordadas esas condiciones, conceder a los usuarios la autorización que legitima la utilización de dichas obras. Adicionalmente, la persona jurídica se encarga de monitorear la 
utilización de las obras cuya gestión se le encomendó, recaudar las remuneraciones pactadas de las personas que hayan usado su repertorio $y$, finalmente, distribuir entre los titulares de derechos de autor cuyos derechos administra las regalías obtenidas sobre la base de algún criterio de distribución establecido para el efecto.

La descripción anterior permite resaltar un punto que tendrá un papel importante en la solución de este caso: la función de las sociedades de gestión colectiva las pone en contacto con dos tipos de agentes. De un lado, con los titulares de derechos de autor, a quienes les ofrecen el servicio de gestión y, una vez efectuado el recaudo, les distribuyen los ingresos percibidos por la utilización de las obras. Del otro, con los usuarios de esas creaciones, en relación con quienes desarrollan la gestión correspondiente mediante la negociación de las condiciones de uso, la concesión de la autorización necesaria y la ejecución de las labores de recaudo.

Es importante resaltar que las sociedades de gestión colectiva gozan de prerrogativas específicas de las que carece la gestión individual, tanto la que realiza el titular directamente como aquella que adelanta por medio de formas asociativas distintas a la gestión colectiva. Ejemplo de estas ventajas se encuentra en la denominada legitimación presunta, prevista, según la DNDA, en los artículos 49 de la Decisión 351 de 1993 y 9 del Decreto 3942 de 2010.

De otra parte, la descripción de la dinámica de la gestión colectiva que se ha expuesto también permite identificar las razones económicas que justifican la creación y la función de las sociedades de gestión colectiva. Sobre el particular, la doctrina y la práctica internacional son fuentes que evidencian que la justificación económica de la gestión colectiva consiste en la disminución de, entre otros, tres tipos de costos asociados al ejercicio de los derechos de autor de contenido patrimonial: los costos de búsqueda, los costos negociación y los costos de ejecución del contrato.

\section{Posición de DOMinio de SAYCo}

En relación con la posición dominante de Sayco en el mercado relevante, el informe motivado señaló que (i) Sayco es la única sociedad de gestión colectiva en Colombia que desarrolla esa actividad y (ii) existen barreras económicas y legales que han hecho que sea casi imposible competir con Sayco:

SAYCO es la única persona que desarrolla esta actividad (la gestión colectiva de derechos de autor de contenido patrimonial de obras musicales) en el territorio colombiano $[\ldots][\mathrm{N}] \mathrm{o}$ existe un competidor actual que en un esquema de gestión conjunta pueda ejercer alguna presión competitiva sobre SAYCO $[\ldots]$

[...] Así las cosas, es claro que cualquier persona interesada en prestar servicios de gestión de derechos que interesan en esta actuación mediante estructura propia de la gestión colectiva tendrá notorias dificultades para satisfacer los requisitos legales 
aludidos. (A manera de ejemplo, nótese que se le dificultará vincular a 100 titulares para que le confíen la gestión de sus derechos, pues ellos seguramente preferirán a SAYCO, que además de gozar del reconocimiento y preferencia de los usuarios de las obras, cuenta con prerrogativas para cobrar eficientemente y contratos de reciprocidad alrededor del mundo.

Por lo anterior, Sayco, aprovechándose de esas condiciones, ha establecido una barrera artificial en mercados en los que no tiene posición de dominio, imponiendo la gestión colectiva en todas las modalidades de uso del derecho de comunicación pública.

\section{SigNIFICADO PRÁCTICO}

Teniendo en cuenta que esta es la primera vez en que se declara la posición de dominio de Sayco por parte de la sic, y que de acuerdo con la normatividad establecida por el Decreto 2153 de 1992 al agente de mercado que ostente dominancia se le exige mayor cuidado en su actuar.

Con la recomendación 7.3. que del informe motivado analizado la Delegatura está recomendando al Superintendente que instruya a Sayco para que realice los ajustes correspondientes para que el titular de derechos de autor tenga la posibilidad de elegir qué modalidades del derecho de autor gestiona a través de Sayco y cuáles de otra forma, incluida la individual.

Esto significa que, de aceptar esa recomendación el Superintendente, las editoras y cualquier titular van a poder decir qué derechos patrimoniales y qué modalidades de uso de cada uno de ellos gestionarán por medio de Sayco y cuáles a través de otras formas de administración.

Una posible consecuencia de esta decisión es que entren al mercado formas asociativas independientes que ofrezcan a los titulares de derechos patrimoniales de autor servicios de gestión. Adicionalmente, existe la posibilidad de que Sayco permita a los titulares limitar o revocar parcialmente, para ciertos derechos o modalidades de uso, los mandatos entregados a la sociedad. 